\title{
Steroids for Diabetic Macular Oedema - A Brief Review of the Data
}

\author{
Joshua Kirk and Samantha Fraser-Bell \\ The Save Sight Institute, Sydney Medical School, University of Sydney, Sydney, New South Wales, Australia
}

DOl: https://doi.org/10.17925/EOR.2019.13.1.44

$\mathrm{D}$ abetic macular oedema (DMO) affects up to 20 million people worldwide and is a leading cause of blindness in working-age adults in developed nations. Intravitreal therapies have replaced macular laser over the past decade as the modality of choice for centreinvolving DMO. Anti-vascular endothelial growth factor (anti-VEGF) agents are the current first-line therapy for DMO due to their proven efficacy and side-effect profile. Intravitreal steroids also have proven efficacy and are typically reserved for certain population subsets such as those who have an inadequate response to anti-VEGF agents, pseudophakics or those about to undergo cataract surgery, and in some cases, social or logistical reasons. Of the steroid agents, the dexamethasone intravitreal implant has the most acceptable sideeffect profile and is most commonly utilised. This shift in the way DMO is treated has led to changing patient demographics and an important aspect of future studies will be identifying how to better stratify patients to receive the most appropriate treatment.

\section{Keywords}

Diabetic macular oedema, intravitreal therapy, intravitreal steroids, triamcinolone, fluocinolone, dexamethasone

Disclosures: Joshua Kirk and Samantha Fraser-Bell have no conflicts of interest to declare in relation to this article. Review Process: Double-blind peer review.

Compliance with Ethics: This article involves a review of literature and does not report on new clinical data, or any studies with human or animal subjects performed by any of the authors.

Access: This article is freely accessible at

touchOPHTHALMOLOGY.com.

(C) Touch Medical Media 2019.

Authorship: The named authors meet the International Committee of Medical Journal Editors (ICMJE) criteria

for authorship of this manuscript, take responsibility

for the integrity of the work as a whole, and have given final approval for the version to be published.

Received: 10 January 2019

Accepted: 4 March 2019

Citation: European Ophthalmic Review. 2019;13(1):44-8

Corresponding Author: Joshua Kirk, Sydney Eye Hospital, 8 Macquarie Street, Sydney, NSW 2000, Australia.E: joshuakirk@uni.sydney.edu.au

Support: No funding was received in the publication of this article.
Diabetic macular oedema (DMO) is a complication of diabetic retinopathy and is a leading cause of blindness in working-age adults in developed nations. In 2015, there were an estimated 415 million people with diabetes worldwide. ${ }^{1}$ This number is predicted to rise to 642 million by 2040. ${ }^{1}$ The prevalence of DMO is estimated to be up to $6.8 \%$ in patients with diabetes. ${ }^{2}$ As diabetes prevalence increases worldwide, a concomitant rise in DMO cases is also expected. This will have a significant impact worldwide with growing numbers of patients with visual impairment or loss, increasing healthcare costs and decreasing social and work participation..$^{3-5}$ The purpose of this review is to provide a brief summary of the randomised controlled data for the use of intravitreal steroids in the managemeznt of DMO. It will highlight the strengths and limitations of steroids as well as offering a perspective on their current and future use.

\section{Pathogenesis and risk factors}

The pathogenesis of DMO appears to be multifactorial, with the hallmark feature being breakdown of the blood-retinal-barrier. Prolonged hyperglycaemia induces several biochemical pathways that ultimately lead to increased oxidative stress, inflammation, and impaired vascular function. ${ }^{6}$ Upregulation of growth factors and cytokines, such as vascular endothelial growth factor (VEGF), angiopoietins, tumour necrosis factor, interleukins, and matrix metalloproteinases contribute to disruption of the blood-retinal-barrier and development of DMO. The major modifiable risk factors for DMO are hyperglycaemia, blood pressure and cholesterol. ${ }^{2}$ The Wisconsin Epidemiologic Study of Diabetic Retinopathy (WESDR), a large population-based study, found that the incidence of DMO over 10 years was associated with higher glycosylated haemoglobin levels.? The landmark Diabetes Control and Complications Trial (DCCT) and United Kingdom Prospective Diabetes Study (UKPDS) both provided strong evidence that tight glycaemic control was associated with a reduced risk of development and progression of diabetic retinopathy and DMO., The UKPDS study showed that reducing blood pressure slowed the progression of diabetic retinopathy and vision impairment." The Fenofibrate and Event Lowering in Diabetes (FIELD) and Action to Control Cardiovascular Risk in Diabetes (ACCORD) trials suggested that fenofibrate may have a beneficial role in the management of diabetic retinopathy independent of its action on lipid levels. 10,11

With regards to natural history, the WESDR study reported a $29.0 \%$ incidence of DMO over a period of 25 years in people with type 1 diabetes. In patients with type 2 diabetes, an incidence of $25.4 \%$ in those requiring insulin and $13.9 \%$ in those not requiring insulin was reported. ${ }^{7}$ The DCCT study showed that $27 \%$ of people with type 1 diabetes developed macular oedema within 9 years of diabetes onset. ${ }^{8}$ DMO tends to display a chronic course with progressive visual impairment being a common occurrence without intervention. ${ }^{12}$

\section{Assessment and management}

DMO can be classified as centre- or non-centre-involving. This can be observed clinically by slit lamp biomicroscopy; however, the gold standard of diagnosis in current practice is evaluation 
Figure 1: Imaging in diabetic macular oedema

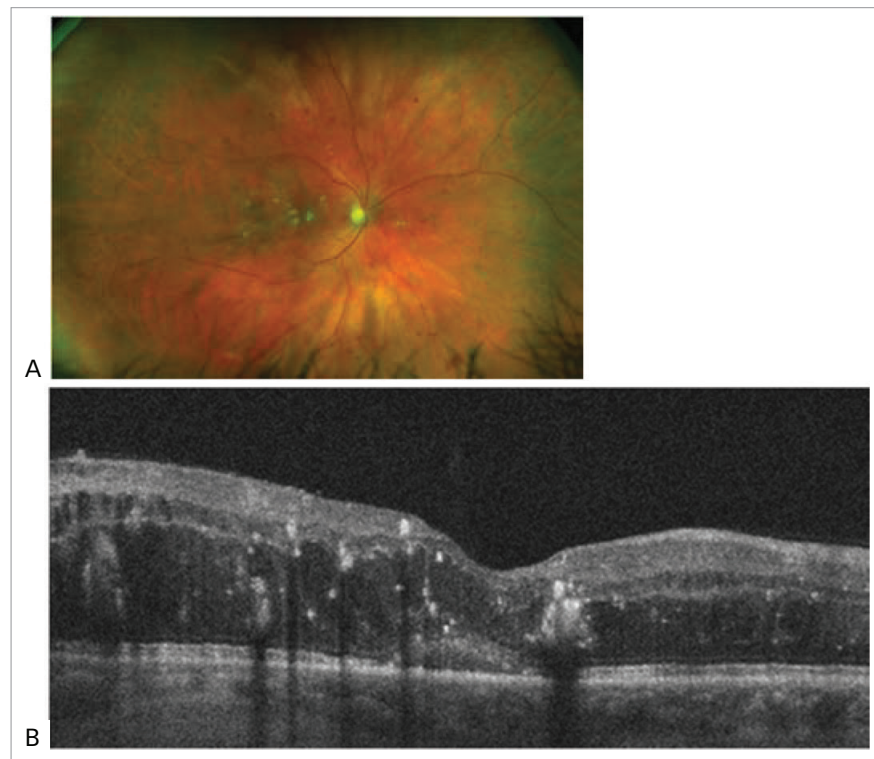

A: Wide field fundus photograph showing clinical appearance of centre-involving diabetic macular oedema. B: Corresponding optical coherence tomography imaging of the same patient showing retinal thickening, cystic changes and sub-retinal fluid.

by optical coherence tomography, which allows objective qualitative and quantitative assessment of the central macula (Figure 1).

Primary and secondary prevention, by maintaining tight glycaemic control and modifying other systemic risk factors such as blood pressure and lipid profile, are important aspects in the management of $\mathrm{DMO} .^{2,7-9}$ Close monitoring of these factors in a multidisciplinary setting should be encouraged. Prior to the development of intravitreal therapies, macular laser was the standard of care for the treatment of DMO. ${ }^{13}$ Anti-VEGF agents are the current first-line therapy for centre-involving DMO. Several large, prospective studies have established the benefit of the anti-VEGF agents ranibizumab, ${ }^{14,15}$ bevacizumab, ${ }^{16}$ and more recently, aflibercept. ${ }^{17}$ A Cochrane review comparing anti-VEGF agents to focal laser therapy concluded there is strong evidence for the use of anti-VEGF agents in the treatment of DMO ${ }^{18}$ Not all eyes with $\mathrm{DMO}$ respond adequately to anti-VEGF agents, however, and intravitreal steroid therapy can be considered as a second-line therapy in these cases. Two large, prospective trials showed persistent macular oedema in $23 \%$ of patients receiving 2 years of intravitreal ranibizumab, indicating a need for alternate therapies in those patients not responsive to anti-VEGF therapy. ${ }^{15}$

\section{Summary of evidence for use of steroids}

For the purpose of this review, only prospective, randomised studies with at least 25 patients per arm and follow-up of at least 12 months were included. Combination therapy with intravitreal anti-VEGF agents and steroids will be considered separately.

\section{Triamcinolone}

The Triamcinolone for Diabetic Macular Oedema (TDMO) study by Gillies et al. was the first prospective randomised study of an intravitreal steroid for DMO. ${ }^{19}$ The TDMO study compared intravitreal triamcinolone (Kenacort ${ }^{\circledR}$ 40, Bristol-Myers Squibb Pharmaceuticals, Australia) to placebo in 69 eyes from patients with DMO refractive to macular laser therapy. After 2 years, the vision in $56 \%$ eyes treated with triamcinolone improved by $\geq 5.0$ letters compared with $26 \%$ eyes in the placebo group. The mean best corrected visual acuity (BCVA) in triamcinolone-treated eyes improved 5.7 letters more than placebo-treated eyes. A greater mean reduction in central macular thickness (CMT) was also noted in the steroid-treated eyes. These findings are summarised in Table 1 along with the result of other clinical trials of intravitreal steroids for DMO. Cataract development and raised intraocular pressure (IOP) were more common in the triamcinolone group. ${ }^{19}$ Complication rates with regards to cataract development and raised IOP requiring treatment are summarised in Table 2 along with those from the other studies described. After 2 years, an open label extension of the TDMO study allowed patients initially randomised to the placebo group to receive triamcinolone. After 5 years similar improvements in visual acuity between both the groups were found, suggesting that delayed initiation of triamcinolone (after 2 years) did not adversely affect longer-term visual outcomes. ${ }^{20}$

The Diabetic Retinopathy Clinical Research Network (DRCRnet) performed a large prospective trial (Protocol B) comparing 840 eyes randomised to receive either macular laser, $1 \mathrm{mg}$ triamcinolone, or $4 \mathrm{mg}$ triamcinolone. ${ }^{21}$ The study allowed for re-treatment at 4 monthly intervals for persistent or new oedema. After 4 months the mean BCVA was better in the $4 \mathrm{mg}$ triamcinolone group compared to both the laser group and the $1 \mathrm{mg}$ triamcinolone groups. After 2 years, however, the laser group demonstrated a better BCVA than either of the triamcinolone groups. The 3 -year results were consistent with those at 24 months in the patients available for follow up. ${ }^{22}$ Raised IOP and development of cataract were more common in the groups receiving steroids. Differences in baseline characteristics may explain the contradicting conclusions of the DRCRnet Protocol B and TDMO studies. ${ }^{23}$ The DRCRnet study actively excluded eyes that investigators thought unlikely to benefit from macular laser treatment and thus the included eyes on average had milder disease.

Another large randomised trial published by Elman et al. included 854 eyes and compared $4 \mathrm{mg}$ triamcinolone (Trivaris ${ }^{\mathrm{TM}}$, Allergan, NJ, USA) combined with laser versus ranibizumab plus prompt or deferred laser versus laser alone for the management of centre-involving DMO. ${ }^{24,25}$ After 12 months, ranibizumab-treated eyes had gained a mean of 9 letters compared to an improvement of 4 letters in the triamcinolone group. Subgroup analysis of pseudophakic eyes at baseline revealed similar visual outcomes in both the triamcinolone and ranibizumab groups. Raised IOP and cataract surgery were more common in the triamcinolone-treated eyes. After 2 years, the trial became open label and the original groups assigned to triamcinolone combined with laser or laser alone were given the opportunity to initiate ranibizumab therapy. ${ }^{26}$ These groups, on average, had a gradual improvement in visual acuity after receiving ranibizumab. Despite the modest improvement in these groups over the 5 years of the study, eyes receiving ranibizumab therapy from the outset were more likely to have better long-term visual outcomes.

\section{Fluocinolone}

Fluocinolone acetonide is a highly lipophilic and potent corticosteroid that was developed as a surgically implanted, non-biodegradable device that releases $0.59 \mu \mathrm{g} /$ day of fluocinolone over 3 years (Retisert ${ }^{\circledR}$, Bausch and Lomb Inc, Rochester, NY, USA). ${ }^{27}$ A prospective randomised clinical trial by Pearson et al., comparing the Retisert implant versus macular laser or observation, was carried out in 196 eyes with treatment refractory DMO ${ }^{28}$ After 3 years, BCVA had improved by $\geq 3$ lines in $31 \%$ of the Retisert-implanted eyes versus $20 \%$ in the standard of care group. The Retisert device, however, had high rates of steroid-induced side effects including raised IOP and cataract development and has not been approved for use. Fluocinolone acetonide was later developed into a smaller intravitreal device (lluvien ${ }^{\circledR}$, Alimera, Alpharetta, GA, USA) that can be introduced via a 25-gauge needle in an outpatient setting. 
Table 1: Summary of efficacy reported in randomised clinical trials of intravitreal steroid therapy for diabetic macular oedema

\begin{tabular}{|c|c|c|c|c|c|c|c|}
\hline Study & Agent and comparator(s) & Dose & Duration & $\begin{array}{l}\text { Number of eyes } \\
\text { in study }\end{array}$ & $\begin{array}{l}\text { VA gain more than } \\
15 \text { letters }\end{array}$ & Mean VA gain & $\begin{array}{l}\text { CMT reduction } \\
(\mu \mathrm{m})\end{array}$ \\
\hline TDMO $(2006)^{19}$ & $\begin{array}{l}\left.\text { Triamcinolone (Kenacort }{ }^{\circledR} 40\right) \\
\text { Placebo }\end{array}$ & $\begin{array}{l}4 \mathrm{mg} \\
\mathrm{N} / \mathrm{A}\end{array}$ & 2 years & 69 & $\begin{array}{l}56 \% \\
26 \%\end{array}$ & $\begin{array}{l}3.1 \\
-2.9\end{array}$ & $\begin{array}{l}125 \\
71\end{array}$ \\
\hline $\begin{array}{l}\text { DRCRnet } \\
\text { Protocol B } \\
(2009)^{22}\end{array}$ & $\begin{array}{l}\text { Triamcinolone (Trivaris }{ }^{\mathrm{TM}} \text { ) } \\
\text { Focal/grid laser }\end{array}$ & $\begin{array}{l}1 \mathrm{mg} \\
4 \mathrm{mg} \\
\mathrm{N} / \mathrm{A}\end{array}$ & 2 years & 840 & $\begin{array}{l}15 \% \\
16 \% \\
20 \%\end{array}$ & $\begin{array}{l}-2 \\
-3 \\
1\end{array}$ & $\begin{array}{l}86 \\
77 \\
139\end{array}$ \\
\hline $\begin{array}{l}\text { DRCRnet } \\
\text { Protocol I } \\
(2010)^{25}\end{array}$ & $\begin{array}{l}\text { Triamcinolone } \text { (Trivaris }^{\mathrm{TM}} \text { ) } \\
\text { Sham + prompt laser } \\
\text { Ranibizumab + prompt laser } \\
\text { Ranibizumab + deferred laser }\end{array}$ & $\begin{array}{l}4.0 \mathrm{mg} \\
\mathrm{N} / \mathrm{A} \\
0.5 \mathrm{mg} \\
0.5 \mathrm{mg}\end{array}$ & 2 years & 854 & $\begin{array}{l}22 \% \\
18 \% \\
29 \% \\
28 \%\end{array}$ & $\begin{array}{l}2^{\dagger} \\
1 \\
7 \\
9\end{array}$ & $\begin{array}{l}107 \\
138 \\
141 \\
150\end{array}$ \\
\hline $\begin{array}{l}\text { Retisert for DMO } \\
(2011)^{28}\end{array}$ & $\begin{array}{l}\text { Fluocinolone (Retisert }{ }^{\circledR} \text { ) } \\
\text { Laser/observation (SOC) }\end{array}$ & $\begin{array}{l}0.59 \mathrm{mg} \\
\mathrm{N} / \mathrm{A}\end{array}$ & 4 years & 196 & $\begin{array}{l}31 \% \\
20 \%\end{array}$ & Not reported & Not reported \\
\hline PLACID $(2013)^{31}$ & $\begin{array}{l}\text { Dexamethasone (Ozurdex }{ }^{\circledR} \text { ) } \\
\text { Sham }\end{array}$ & $\begin{array}{l}0.7 \mathrm{mg} \\
\mathrm{N} / \mathrm{A}\end{array}$ & 1 year & 253 & $\begin{array}{l}28 \%^{*} \\
24 \%\end{array}$ & $\begin{array}{l}3 \\
1\end{array}$ & $\begin{array}{l}100 \\
125\end{array}$ \\
\hline MEAD $(2014)^{30}$ & $\begin{array}{l}\text { Dexamethasone (Ozurdex }{ }^{\circledR} \text { ) } \\
\text { Sham }\end{array}$ & $\begin{array}{l}0.35 \mathrm{mg} \\
0.70 \mathrm{mg} \\
\text { N/A }\end{array}$ & 3 years & 1,048 & $\begin{array}{l}18 \% \\
22 \% \\
12 \%\end{array}$ & $\begin{array}{l}3.6 \\
3.5 \\
2\end{array}$ & $\begin{array}{l}108 \\
112 \\
42\end{array}$ \\
\hline $\begin{array}{l}\text { BEVORDEX } \\
(2016)^{33}\end{array}$ & $\begin{array}{l}\text { Dexamethasone (Ozurdex }{ }^{\circledR} \text { ) } \\
\text { Bevacizumab }\end{array}$ & $\begin{array}{l}0.70 \mathrm{mg} \\
1.25 \mathrm{mg}\end{array}$ & 2 year & 88 & $\begin{array}{l}43 \%{ }^{*} \\
45 \%\end{array}$ & $\begin{array}{l}6.9 \\
9.6\end{array}$ & $\begin{array}{l}150 \\
148\end{array}$ \\
\hline OZLASE $(2015)^{35}$ & $\begin{array}{l}\text { Dexamethasone (Ozurdex }{ }^{\circledR} \text { ) } \\
\text { Laser }\end{array}$ & $\begin{array}{l}0.7 \mathrm{mg} \\
\mathrm{N} / \mathrm{A}\end{array}$ & 1 year & 80 & $\begin{array}{l}16 \% \\
5 \%\end{array}$ & $\begin{array}{l}-0.3 \\
0.4\end{array}$ & $\begin{array}{l}157^{\ddagger} \\
71^{\ddagger}\end{array}$ \\
\hline $\begin{array}{l}\text { Callanan et al. } \\
(2017)^{34}\end{array}$ & $\begin{array}{l}\text { Dexamethasone (DEX implant) } \\
\text { Ranibizumab }\end{array}$ & $0.7 \mathrm{mg}$ & 1 year & 363 & $\begin{array}{l}12 \% \\
25 \%\end{array}$ & $\begin{array}{l}4.3 \\
7.6\end{array}$ & $\begin{array}{l}174 \\
164\end{array}$ \\
\hline
\end{tabular}

${ }^{*}$ VA gain $>10$ letters: ${ }^{\dagger}$ Eight in pseudophakic group: ${ }^{*}$ Change in median CMT.

CMT = central macular thickness; DMO = diabetic macular oedema; DRCRnet = Diabetic Retinopathy Clinical Research Network; N/A = not applicable; SOC = standard of care VA = visual acuity.

Table 2: Summary of effects of intravitreal steroid therapy on intraocular pressure and cataract rates in randomised clinical trials of intravitreal steroids for diabetic macular oedema

\begin{tabular}{|c|c|c|c|c|c|c|}
\hline Study & Steroid agent & Dose & Duration & $\begin{array}{l}\text { Raised IOP } \\
\text { (>10 mmHg rise) }\end{array}$ & $\begin{array}{l}\text { Required laser/ } \\
\text { incisional } \\
\text { glaucoma surgery }\end{array}$ & $\begin{array}{l}\text { Required } \\
\text { cataract surgery }\end{array}$ \\
\hline TDMO $(2006)^{19}$ & Triamcinolone (Kenacort ${ }^{\circledR} 40$ ) & $4 \mathrm{mg}$ & 2 years & $68 \%$ (>5 mmHg rise) & $6 \%$ & $54 \%$ \\
\hline $\begin{array}{l}\text { DRCRnet Protocol B } \\
(2009)^{22}\end{array}$ & Triamcinolone (Trivaris ${ }^{\mathrm{TM}}$ ) & $\begin{array}{l}1 \mathrm{mg} \\
4 \mathrm{mg}\end{array}$ & 2 years & $\begin{array}{l}18 \% \\
33 \%\end{array}$ & $\begin{array}{l}0 \% \\
5 \%\end{array}$ & $\begin{array}{l}46 \% \\
83 \%\end{array}$ \\
\hline Retisert for DMO $(2011)^{28}$ & Fluocinolone (Retisert ${ }^{\circledR}$ ) & $0.59 \mathrm{mg}$ & 4 years & $61 \%(\mathrm{IOP}>30 \mathrm{mmHg})$ & $34 \%$ & $91 \%$ \\
\hline FAME $(2012)^{29}$ & Fluocinolone (lluvien ${ }^{\circledR}$ ) & $\begin{array}{l}0.2 \mu g \\
0.5 \mu g\end{array}$ & 3 years & $\begin{array}{l}38 \%^{\dagger} \\
47 \%^{\dagger}\end{array}$ & $\begin{array}{l}5 \% \\
8 \%\end{array}$ & $\begin{array}{l}80 \% \\
87 \%\end{array}$ \\
\hline PLACID $(2013)^{31}$ & Dexamethasone (Ozurdex ${ }^{\circledR}$ ) & $0.7 \mathrm{mg}$ & 1 year & $15 \%$ & $0 \%$ & $3 \%$ \\
\hline MEAD $(2014)^{30}$ & Dexamethasone (Ozurdex ${ }^{\circledR}$ ) & $\begin{array}{l}0.35 \mathrm{mg} \\
0.70 \mathrm{mg}\end{array}$ & 3 years & $\begin{array}{l}25 \% \\
28 \%\end{array}$ & $\begin{array}{l}0.3 \% \\
0.6 \%\end{array}$ & $\begin{array}{l}52 \% \\
59 \%\end{array}$ \\
\hline BEVORDEX $(2016)^{33}$ & Dexamethasone (Ozurdex $\left.{ }^{\circledR}\right)$ & $0.7 \mathrm{mg}$ & 2 years & 74\% (>5 mmHg rise) & $0 \%$ & $37 \%$ \\
\hline OZLASE $(2015)^{35}$ & Dexamethasone (Ozurdex ${ }^{\circledR}$ ) & $0.7 \mathrm{mg}$ & 1 year & $20 \%^{\dagger}$ & $0 \%$ & $33 \%$ \\
\hline Callanan et al. $(2017)^{34}$ & Dexamethasone (Ozurdex ${ }^{\circledR}$ ) & $0.7 \mathrm{mg}$ & 1 year & $34 \%$ & $0.6 \%$ & $4 \%$ \\
\hline
\end{tabular}

*IOP rise $>10 \mathrm{mmHg}, I O P>30 \mathrm{mmHg}$ or initiation of IOP lowering treatment; ${ }^{\dagger}$ IOP lowering drops commenced.

$D M O=$ diabetic macular oedema; DRCRnet = Diabetic Retinopathy Clinical Research Network; IOP = intraocular pressure. 
The Fluocinolone Acetonide Intravitreal Implant for Diabetic Macular Edema (FAME) study was a prospective randomised controlled trial by Campochiaro et al. that included 953 eyes randomised to receive low-dose fluocinolone insert ( $0.2 \mu \mathrm{g} /$ day), high-dose insert ( $0.5 \mu \mathrm{g} /$ day) or a sham injection in patients with DMO refractory to laser treatment. ${ }^{29}$ After 3 years, an improvement in BCVA of $\geq 15$ letters was achieved in $29 \%$ of the low-dose steroid group and in $28 \%$ of the high-dose versus $19 \%$ of the sham group. A subgroup analysis of patients with DMO greater than 3 years duration at baseline showed an even greater benefit for the fluocinolone insert compared to control. Steroid-induced side effects were again common in both high- and low-dose fluocinolone groups (Table 2).

\section{Dexamethasone}

The dexamethasone intravitreal implant (DEX implant; Ozurdex ${ }^{\oplus}$, Allergan Inc., Irvine, CA, USA), a biodegradable, slow-release form of dexamethasone, has been manufactured for intravitreal use. The MEAD study was a large prospective trial that randomised 1,048 patients with $\mathrm{DMO}$ in a 1:1:1 ratio to treatment with $0.7 \mathrm{mg}$ DEX implant, 0.35 dexamethasone mg DEX implant, or sham procedure. ${ }^{30}$ It included patients with BCVA 20/50-20/200 Snellen equivalent, and CMT greater than $300 \mu \mathrm{m}$. Of patients in the $0.7 \mathrm{mg}$ group, $22.2 \%$ showed an improvement of $\geq 15$ letters compared to $18.4 \%$ in the $0.35 \mathrm{mg}$ group and $12 \%$ in the sham group. Mean CMT reduction from baseline was also greater in the groups receiving DEX implant compared to sham. Raised IOP and cataract surgery rates were more common in the steroidtreated groups. It became apparent during the study that the DEX implant lost effectiveness before 6 months and protocol amendments were made reflecting this. The study was also limited by significant loss to follow-up, with over $30 \%$ of patients in the DEX implant treatment groups and $50 \%$ of patients in the sham group exiting the study prior to completion. ${ }^{30}$

The PLACID study was a prospective trial that randomised 253 eyes to either the DEX implant followed by macular laser at 1 month or to sham injection followed by macular laser at 1 month in the treatment of diffuse DMO. ${ }^{31}$ No statistical difference between the two groups was found, with $27.8 \%$ of the DEX implant-treated eyes gaining $>10$ BCVA letters at 12 months compared with $23.6 \%$ in the sham group. However, a significantly greater improvement in BCVA was demonstrated at various time points up to 9 months in the eyes treated with DEX implant. This was also evident across time based on area under the curve analysis. As expected, a greater proportion of eyes treated with DEX implant experienced a rise in IOP. ${ }^{31}$

The BEVORDEX study was the first head-to-head clinical trial comparing bevacizumab versus DEX implant for centre-involving DMO either unresponsive or unlikely to benefit from laser treatment. ${ }^{32}$ Eighty-eight eyes were randomised to receive $1.25 \mathrm{mg}$ bevacizumab up to every 4 weeks or the DEX implant up to every 16 weeks. Both treatments were given pro re nata. Forty-one percent of DEX implant-treated eyes improved by $\geq 10$ logMAR letters at 12 months compared to $40 \%$ of bevacizumab-treated eyes. The DEX implant group had superior anatomic outcomes with regards to CMT and required fewer injections. Eleven percent of the DEX implant-treated eyes lost $\geq 10$ letters compared with none in the bevacizumab group. Four of these cases were due to cataract development and one was due to chorioretinitis in a patient with undiagnosed secondary syphilis. No eyes in either group required incisional glaucoma surgery. These results were maintained at 24 months, with $43 \%$ of DEX implant-treated eyes demonstrating a $>10$-letter improvement from baseline compared to $45 \%$ of bevacizumab-treated eyes. ${ }^{33}$ As expected, rates of cataract surgery and raised IOP were higher in the DEX implant groups.

A multicentre, open-label, randomised trial of 363 patients by Callanan et al. was the first study to compare the DEX implant with a licensed anti-VEGF agent (ranibizumab) for the treatment of DMO ${ }^{34}$ Patients were treated with the DEX implant at baseline, 5 and 10 months, and ranibizumab was given every 4 weeks until maximum visual acuity was achieved and stable over three visits. Treatments could then be suspended but allowed to recommence if a decrease in BCVA occurred. The mean average BCVA improvement over 1 year was 4.34 letters in the dexamethasone group and 7.60 letters in the ranibizumab group. Based on these results, it was concluded that the DEX implant was non-inferior to ranibizumab. Cataract surgery was performed on seven patients in the dexamethasone group and one patient in the ranibizumab group. Greater rates of raised IOP were reported in the dexamethasone group. ${ }^{34}$ The OZLASE study was a prospective study that enrolled 80 patients with centre-involving DMO. ${ }^{35}$ Inclusion criteria for BCVA was between 54-78 logMAR letters. Eighty patients were randomised equally to either combination therapy with DEX implant and macular laser or macular laser only. In contrast with the BEVODEX $X^{33}$ and MEAD ${ }^{30}$ studies, no significant difference in BCVA was found between the two study groups. At 12 months, the mean change in BCVA was - 0.3 letters in the combination group and +0.4 letters in the macular laser group. CMT was significantly reduced in the combination group compared to the laser group. The authors postulated that this unexpected result was due to a ceiling effect on BCVA. Visual acuity inclusion criteria in the BEVORDEX and MEAD studies were 17-72 and 34-68 logMAR letters, respectively, and thus patients in these studies theoretically had a greater potential for improvement. Cataract surgery and elevated IOP requiring topical therapy were more common in the combination group. ${ }^{35}$

\section{Combination therapy}

A number of randomised controlled trials have examined the effects of combining anti-VEGF agents with intravitreal steroids compared to monotherapy with anti-VEGF agents, steroids or macular laser alone. In 2008, Ahmadieh et al. compared intravitreal bevacizumab (1.25 mg) with or without triamcinolone $(1.25 \mathrm{mg}$ ) compared to sham injection in patients with refractory DMO. ${ }^{36}$ Both groups showed significant improvement in BCVA and CMT compared to placebo; however, no difference was found between the bevacizumab and combination therapy groups. A randomised trial by Soheilian et al., comparing $1.25 \mathrm{mg}$ bevacizumab alone or combined with $2 \mathrm{mg}$ triamcinolone versus laser, showed a significant improvement in BCVA in the bevacizumab monotherapy group compared to the combination and laser groups at 6 months. ${ }^{37}$ This effect was not sustained, however, and after 24 months there was no significant difference between the bevacizumab and combination groups..$^{38}$ Lim et al. compared bevacizumab (1.25 $\mathrm{mg}$ ) versus triamcinolone (2 $\mathrm{mg}$ ) versus combination therapy with both. No significant difference in BCVA and CMT was observed between the three groups at 12 months. ${ }^{39}$ Another study by Neto et al. evaluated the efficacy of combination therapy with bevacizumab (1.25 mg) and triamcinolone (4 mg) compared to monotherapy with either treatment alone. ${ }^{40}$ All groups showed significant improvements in BCVA; however, no differences between groups were observed. A 2017 study by RiaziEsfahani et al. assessed bevacizumab $(1.25 \mathrm{mg})$ alone or in combination with triamcinolone $(1 \mathrm{mg}){ }^{41}$ After 6 months, BCVA improvement was significantly better in the bevacizumab monotherapy group.

Anti-VEGF agents in combination with DEX implant have also been studied in patients with refractory DMO. Maturi et al. compared the effect of DEX implant in combination with bevacizumab $(1.25 \mathrm{mg})$ versus bevacizumab 
monotherapy in eyes with incomplete response to prior anti-VEGF monotherapy. ${ }^{42}$ Combination therapy significantly improved BCVA and CMT, although vision changes were not significantly improved compared to the intravitreal bevacizumab monotherapy group. DRCRnet Protocol U compared continued ranibizumab monotherapy versus ranibizumab plus DEX implant in eyes with persistent DMO despite anti-VEGF treatment. ${ }^{43}$ The study found that combination therapy did not significantly improve BCVA at 6 months compared to ranibizumab alone. A recent Cochrane review found insufficient evidence to suggest combination therapy is better than monotherapy with anti-VEGF agents as first-line treatment for DMO. ${ }^{44}$ Consistent with previous studies, eyes receiving anti-VEGF plus steroids had a greater risk of elevated IOP and cataract development compared with those receiving anti-VEGF alone.

\section{Conclusion}

Trials investigating the use of intravitreal steroids for the treatment of DMO have reported mixed results. A key challenge lies in identifying the subset of patients likely to benefit from intravitreal steroids. Data from subgroup analyses in the MEAD ${ }^{30}$ and BEVORDEX ${ }^{33}$ trials suggest that the DEX implant may be considered as a first-line treatment option in pseudophakic eyes. There is significant interest in following up real-world data after the completion of trials and determining whether treatments have sustained benefit beyond the relatively short time periods inherent to clinical studies. Patients are likely to have closer monitoring with more regular follow-up and timely access to treatment during the trial period, and thus favourable trial results may not be reflected in the real-world setting. A systematic review and meta-analysis of real-world studies evaluating the efficacy of the DEX implant for patients with DMO non-responsive to anti-VEGF therapy suggested a clinical benefit in improving BCVA. ${ }^{45}$ Another challenge remains in defining non-response or suboptimal response to anti-VEGF treatment and in identifying the optimal timing for switching to intravitreal steroids. Patient factors also need to be considered; reduced treatment burden from fewer injections compared to anti-VEGF therapy make intravitreal steroids a more attractive treatment option for some patients. Frequent clinic visits may be impractical, especially those with complex co-morbidities associated with diabetes.

A developing challenge is adapting to the changing landscape of patient demographics. Pharmacological treatments have been available for several years and treatment-naïve eyes are becoming less common. As a result, clinicians are increasingly managing patients who have been receiving treatment for many years and who may have reached a ceiling of potential improvement, regardless of which treatment option has been chosen. Anti-VEGF agents and intravitreal steroids both improve vision, but their effect diminishes with time and re-treatment is necessary. Patients must be followed up regularly to assess treatment response and manage potential side effects. Ongoing multidisciplinary evaluation and appropriate optimisation of modifiable risk factors is indicated.
1. Ogurtsova K, da Rocha Fernandes JD, Huang Y, et al. IDF Diabetes Atlas: Global estimates for the prevalence of diabetes for 2015 and 2040. Diabetes Res Clin Pract. 2017:128:40-50. Yau JW, Rogers SL, Kawasaki R, et al. Global prevalence and major risk factors of diabetic retinopathy. Diabetes Care. 2012;35:556-64

3. LamoureuX EL, Hassell JB, Keeffe JE. The impact of diabetic retinopathy on participation in daily living. Arch Ophthalmol 2004;122:84-8.

4. Shea AM, Curtis LH, Hammill BG, et al. Resource use and costs associated with diabetic macular edema in elderly persons. Arch Ophthalmol. 2008;126:1748-54.

5. Minassian DC, Owens DR, Reidy A. Prevalence of diabetic macular oedema and related health and social care resource use in England. Br J Ophthalmol. 2012;96:345-9.

6. Das A, McGuire PG, Rangasamy S. Diabetic macular edema: pathophysiology and novel therapeutic targets. Ophthalmology 2015:122:1375-94

7. Klein R, Klein BE, Moss SE, Cruickshanks KJ. The Wisconsin epidemiologic study of diabetic retinopathy XV: the long-term incidence of macular edema. Ophthalmology. 1995;102:7-16.

8. Diabetes Control and Complications Trial Research Group. The relationship of glycemic exposure (HDA1C) to the risk of development and progression of retinopathy in the diabete control and complications trial. Diabetes. 1995;44:968-83.

9. Matthews D, Stratton I, Aldington S, et al. Risks of progression of retinopathy and vision loss related to tight blood pressure control in type 2 diabetes mellitus: UKPDS 69. Arch Ophthalmol. 2004;122:1631-40

10. Keech AC, Mitchell P, Summanen PA, et al. Effect of fenofibrate on the need for laser treatment for diabetic retinopathy (FIELD study): a randomised controlled trial. Lancet. 2007:370:1687-97.

11. ACCORD Study Group and ACCORD Eye Study Group. Effects of medical therapies on retinopathy progression in type 2 diabetes. N Eng J Med 2010:363:233-44.

12. Fong DS, Ferris III FL, Davis MD, Chew EY. Causes of severe visual loss in the early treatment diabetic retinopathy study: ETDRS report no. 24. Early Treatment Diabetic Retinopathy Study Research Group. Am J Ophthalmol. 1999;127:137-41.

13. Early Treatment Diabetic Retinopathy Study Research Group. Photocoagulation for diabetic macular edema. Early treatment diabetic retinopathy study report number 1. Early Treatment Diabetic Retinopathy Study Research Group. Arch Ophthalmol. 1985;103:1796-806.

14. Mitchell P, Bandello F, Schmidt-Erfurth U, et al. The RESTORE study: ranibizumab monotherapy or combined with laser versus laser monotherapy for diabetic macular edema. Ophthalmology. 2011:118:615-25.

15. Nguyen $\mathrm{QD}$, Brown DM, Marcus DM, et al. Ranibizumab for diabetic macular edema: results from 2 phase III randomized trials: RISE and RIDE. Ophthalmology. 2012;119:789-801.

16. Michaelides M, Kaines A, Hamilton RD, et al. A prospective randomized trial of intravitreal bevacizumab or laser therapy in the management of diabetic macular edema (BOLT study) 12-month data: report 2. Ophthalmology. 2010;117:1078-86.

17. Diabetic Retinopathy Clinical Research Network, Wells JA, Glassman AR, et al. Aflibercept, bevacizumab, or ranibizumab for diabetic macular edema. N Eng J Med. 2015;372:1193-203.
18. Virgili G, Parravano M, Menchini F, Evans JR. Anti-vascular Virgili G, Parravano M, Menchini F, Evans JR. Anti-vascular
endothelial growth factor for diabetic macular oedema. Cochrane Database Syst Rev. 2014(10):CD007419.

19. Gillies MC, sutter FK, simpson JM, et al. Intravitreal triamcinolone for refractory diabetic macular edema: two-yea results of a double-masked, placebo-controlled, randomized clinical trial. Ophthalmology. 2006;113:1533-8.

20. Gillies MC, Simpson JM, Gaston C, et al. Five-year results of a randomized trial with open-label extension of triamcinolone acetonide for refractory diabetic macular edema. Ophthalmology. 2009;116:2182-7.

21. Diabetic Retinopathy Clinical Research Network. A randomized trial comparing intravitreal triamcinolone acetonide and focal/grid photocoagulation for diabetic macular edema. Ophthalmology. 2008;115:1447-59.

22. Diabetic Retinopathy Clinical Research Network, Beck RW, Edwards AR, et al. Three-year follow up of a randomized Edwards AR, et al. Three-year follow up of a randomized trial comparing focal/grid photocoagulation and intravitreal
triamcinolone for diabetic macular edema. Arch Ophthalmol. triamcinolone for

23. Mehta H, Gillies M, Fraser-Bell S. Perspective on the role of Ozurdex (dexamethasone intravitreal implant) in the management of diabetic macular oedema. Ther Adv Chronic Dis. 2015;6:234-45.

24. Elman MJ, Aiello LP, Beck RW, et al. Randomized tria evaluating ranibizumab plus prompt or deferred laser or triamcinolone plus prompt laser for diabetic macular edema. Ophthalmology. 2010;117:1064-77.

25. Elman MJ, Bressler NM, Qin $\mathrm{H}$, et al. Expanded 2-year follow-up of ranibizumab plus prompt or deferred laser or triamcinolone plus prompt laser for diabetic macular edema. Ophthalmology. 2011;118:609-14.

26. Bressler SB, Glassman AR, Almukhtar T, et al. Five-year outcomes of ranibizumab with prompt or deferred laser versus laser or triamcinolone plus deferred ranibizumab for diabetic macular edema. Am J Ophthalmol. 2016;164:57-68.

27. Messenger WB, Beardsley RM, Flaxel CJ. Fluocinolone acetonide intravitreal implant for the treatment of diabetic macular edema. Drug Des Devel Ther. 2013;7:425-34.

28. Pearson PA, Comstock TL, Ip M, et al. Fluocinolone acetonide intravitreal implant for diabetic macular edema: a 3-year multicenter, randomized, controlled clinical trial. Ophthalmology. 2011;118:1580-7.

29. Campochiaro PA, Brown DM, Pearson A, et al. Sustained delivery fluocinolone acetonide vitreous inserts provide benefit for at least 3 years in patients with diabetic macular edema. Ophthalmology. 2012;119:2125-32.

30. Boyer DS, Yoon YH, Belfort R, et al. Three-year, randomized, sham-controlled trial of dexamethasone intravitreal implant in patients with diabetic macular edema. Ophthalmology. 2014:121:1904-14.

31. Callanan DG, Gupta S, Boyer DS, et al. Dexamethasone intravitreal implant in combination with laser photocoagulatio for the treatment of diffuse diabetic macular edema. Ophthalmology. 2013;120:1843-51.

32. Gillies MC, Lim LL, Campain A, et al. A randomized clinical trial of intravitreal bevacizumab versus intravitreal dexamethasone for diabetic macular edema: the BEVORDEX study. Ophthalmology. 2014;121:2473-81.
33. Fraser-Bell S, Lim LL, Campain A, et al. Bevacizumab or dexamethasone implants for DME: 2-year results (The BEVORDEX Study). Ophthalmology 2016:123:1399-401.

34. Callanan DG, Loewenstein A, Patel SS, et al. A multicenter, 12 -month randomized study comparing dexamethasone intravitreal implant with ranibizumab in patients with diabetic macular edema. Graefes Arch Clin Exp Ophthalmol. 2017;255:463-73

35. Heng LZ, Sivaprasad S, Crosby-Nwaobi R, et al. A prospective randomised controlled clinical trial comparing a combination of repeated intravitreal Ozurdex and macular laser therapy versus macular laser only in centre-involving diabetic macular oedema (OZLASE study). Br J Ophthalmol. 2015;100:802-7.

36. Ahmadieh H, Ramezani A, Shoeibi N, et al. Intravitreal bevacizumab with or without triamcinolone for refractory diabetic macular edema; a placebo-controlled, randomized clinical trial. Graefes Arch Clin Exp Ophthalmol. 2008:246:483-9.

37. Soheilian M, Ramezani A, Obudi A, et al. Randomized trial of intravitreal bevacizumab alone or combined with triamcinolone versus macular photocoagulation in diabetic macular edema. Ophthalmology. 2009;116:1142-50

38. Soheilian M, Garfami KH, Ramezani A, et al. Two-year results of a randomized trial of intravitreal bevacizumab alone or combined with triamcinolone versus laser in diabetic macular edema. Retina. 2012;32:314-21.

39. Lim JW, Lee HK, Shin MC. Comparison of intravitreal bevacizumab alone or combined with triamcinolone versus triamcinolone in diabetic macular edema: a randomized clinical trial. Ophthalmologica. 2012;227:100-6.

40. Neto HO, Regatieri CV, Nobrega MJ, et al. Multicenter, randomized clinical trial to assess the effectiveness of intravitreal injections of bevacizumab, triamcinolone, or their combination in the treatment of diabetic macular edema. Ophthalmic Surg Lasers Imaging Retina. 2017;48:734-40.

Riazi-Esfahani M, Riazi-Esfahani H, Ahmadraji A, et al.

41. Riazi-Esfahani M, Riazi-Esfahani $\mathrm{H}$, Ahmadraji A, et al.
Intravitreal bevacizumab alone or combined with $1 \mathrm{mg}$ Intravitreal bevacizumab alone or combined with $1 \mathrm{mg}$
triamcinolone in diabetic macular edema: a randomized clinical trial. Int Ophthalmol. 2018;38:585-98.

42. Maturi RK, Bleau L, Saunders J, et al. A 12-month, singlemasked, randomized controlled study of eyes with persistent diabetic macular edema after multiple anti-VEGF injections to assess the efficacy of the dexamethasone-delayed delivery system as an adjunct to bevacizumab compared with continued bevacizumab monotherapy. Retina. 2015;35:1604-14.

43. Maturi RK, Glassman AR, Liu D, et al. Effect of adding dexamethasone to continued ranibizumab treatment in patients with persistent diabetic macular edema: a DRCR Network phase 2 randomized clinical trial. JAMA Ophthalmo 2018;136:29-38.

44. Mehta $\mathrm{H}$, Hennings $\mathrm{C}$, Gillies MC, et al. Anti-vascular endothelial growth factor combined with intravitreal steroids for diabetic macular oedema. Cochrane Database Syst Rev. 2018:4:CD011599.

45. Khan Z, Kuriakose RK, Khan M, et al. Efficacy of the intravitreal sustained-release dexamethasone implant for diabetic macula edema refractory to anti-vascular endothelial growth factor therapy: meta-analysis and clinical implications. Ophthalmic Surg Lasers Imaging Retina. 2017;48:160-6. 